\title{
Commentary: The Role of the Anion in Salt (NaCl) Detection by Mouse Taste Buds
}

\author{
Vaibhav Menon ${ }^{* t}$ and Yu-Chieh David Chen ${ }^{* t}$ \\ Interdepartmental Neuroscience Program, University of California, Riverside, Riverside, CA, United States
}

Keywords: salt, taste transduction, anion, taste cells, fungiform, amiloride-insensitive

\section{A Commentary on}

The Role of the Anion in Salt ( $\mathrm{NaCl})$ Detection by Mouse Taste Buds

by Roebber, J. K., Roperm, S. D., and Chaudhari, N. (2019). J. Neurosci. 39, 6224-6232. doi: 10.1523/JNEUROSCI.2367-18.2019

Among the five basic taste qualities, much is known about the molecular receptors and corresponding taste receptor cell types in rodent taste buds for sweet, bitter, umami, sour, and low salt taste (Chandrashekar et al., 2010; Liman et al., 2014; Roper and Chaudhari, 2017; Tu et al., 2018). In contrast, the molecular and cellular basis of high salt taste is incompletely understood, despite the known physiological importance of salt in regulating water homeostasis, ion concentration gradients, and sodium appetite (Schulkin, 1991). In addition, excessive sodium consumption in dietary food intake has been linked with hypertension and cardiovascular diseases (Aaron and Sanders, 2013), underscoring the importance of elucidating the high salt transduction pathway and its major molecular components.

Taste buds, the functional units of taste transduction, are located in three morphologically distinct gustatory papillae (circumvallate, foliate, and fungiform) in different parts of the rodent tongue and the palate, which are innervated by different peripheral nerves. There are three morphological types of taste receptor cells (TRCs) in taste buds (Liman et al., 2014; Roper and Chaudhari, 2017): Type 1 TRCs are glial-like cells; Type 2 TRCs express T1R or T2R receptors for detection of sweet, bitter, and umami substances; and Type 3 TRCs express the Otopetrin, a candidate proton channel mediating sour taste. Previous studies have recorded salt responses in the chorda tympani nerve (Hill et al., 1982), which conveys input from the fungiform papilla in the anterior part of the tongue. Depending on its concentration, salt $(\mathrm{NaCl})$ elicits two distinct behavioral responses: appetitive low concentration $(<100 \mathrm{mM})$ and aversive high concentration (>300 mM) responses. Two distinct salt transduction mechanisms have been reported, separable by sensitivity to the diuretic amiloride. The first, an amiloride-sensitive pathway, is $\mathrm{Na}^{+}$-selective for low salt detection, with epithelial sodium channel $\mathrm{ENaC}$ identified as the underlying molecular receptor for mediating low-salt attraction (Vandenbeuch et al., 2008; Yoshida et al., 2009; Chandrashekar et al., 2010). The second, an amiloride-insensitive pathway, is cation non-selective for high salt detection. Notably, the amiloride-insensitive response component is the major contributor $(\sim 80 \%)$ of the overall high salt responses recorded in the chorda tympani nerve in mice (Lu et al., 2016). However, the underlying transduction mechanism and the identity of taste cell types involved in both pathways remain elusive. A recent article in the Journal of Neuroscience by Roebber et al. (2019) reports that amiloride-insensitive high salt transduction occurs in Type 2 TRCs and is largely dependent on the presence of the $\mathrm{Cl}^{-}$anion.

Physiological measurement of salt responses is complex and challenging given that both the cation $\left(\mathrm{Na}^{+}\right)$and anion $\left(\mathrm{Cl}^{-}\right)$are present in extracellular fluids, and the application of hypertonic/hypotonic stimuli to the entire extracellular space may induce non-physiological cellular changes. To circumvent these problems, Roebber et al. (2019) performed ex vivo $\mathrm{Ca}^{2+}$ 
imaging and recorded cellular responses of different taste cell types in a semi-intact preparation of mouse taste buds. This method allows precise spatiotemporal control of tastant delivery to the apical tips of the taste bud cells while maintaining the same ionic concentration in the rest of the cell bodies. By mimicking the in vivo stimulation with salt, the authors reported robust concentration-dependent cellular responses to $\mathrm{NaCl}$ that were amiloride-insensitive. Prolonged stimulation with $\mathrm{NaCl}$ resulted in rapid adaptation of $\mathrm{Ca}^{2+}$ responses (Roebber et al., 2019), consistent with previously described electrophysiological recordings of chorda tympani nerve responses to $\mathrm{NaCl}$ (Beidler, 1953).

Importantly, Roebber et al. (2019) provided several lines of evidence that it is the Type 2 but not Type 3 TRCs that are involved in the amiloride-insensitive responses to high salt. First, post-hoc immunohistochemistry staining showed that TRCs with amiloride-insensitive high salt responses were co-labeled with antibodies against a Type 2 TRC marker (anti-PLCß2) but not a Type 3 TRC marker (anti-Car4). Second, TRCs with amilorideinsensitive high salt responses did not require external $\mathrm{Ca}^{2+}$, characteristic of Type 2 TRCs that utilize internal $\mathrm{Ca}^{2+}$ stores as opposed to Type 3 TRCs that express voltage-gated $\mathrm{Ca}^{2+}$ channels to allow entry of external $\mathrm{Ca}^{2+}$. Finally, sequential application of $\mathrm{NaCl}$ and other diagnostic tastants to the same taste bud showed a broad overlap in populations of cells that responded to both $\mathrm{NaCl}$ and to saccharin or a bitter mixture of cycloheximide and denatonium, which are known to activate Type 2 TRCs. This result is consistent with a previous study

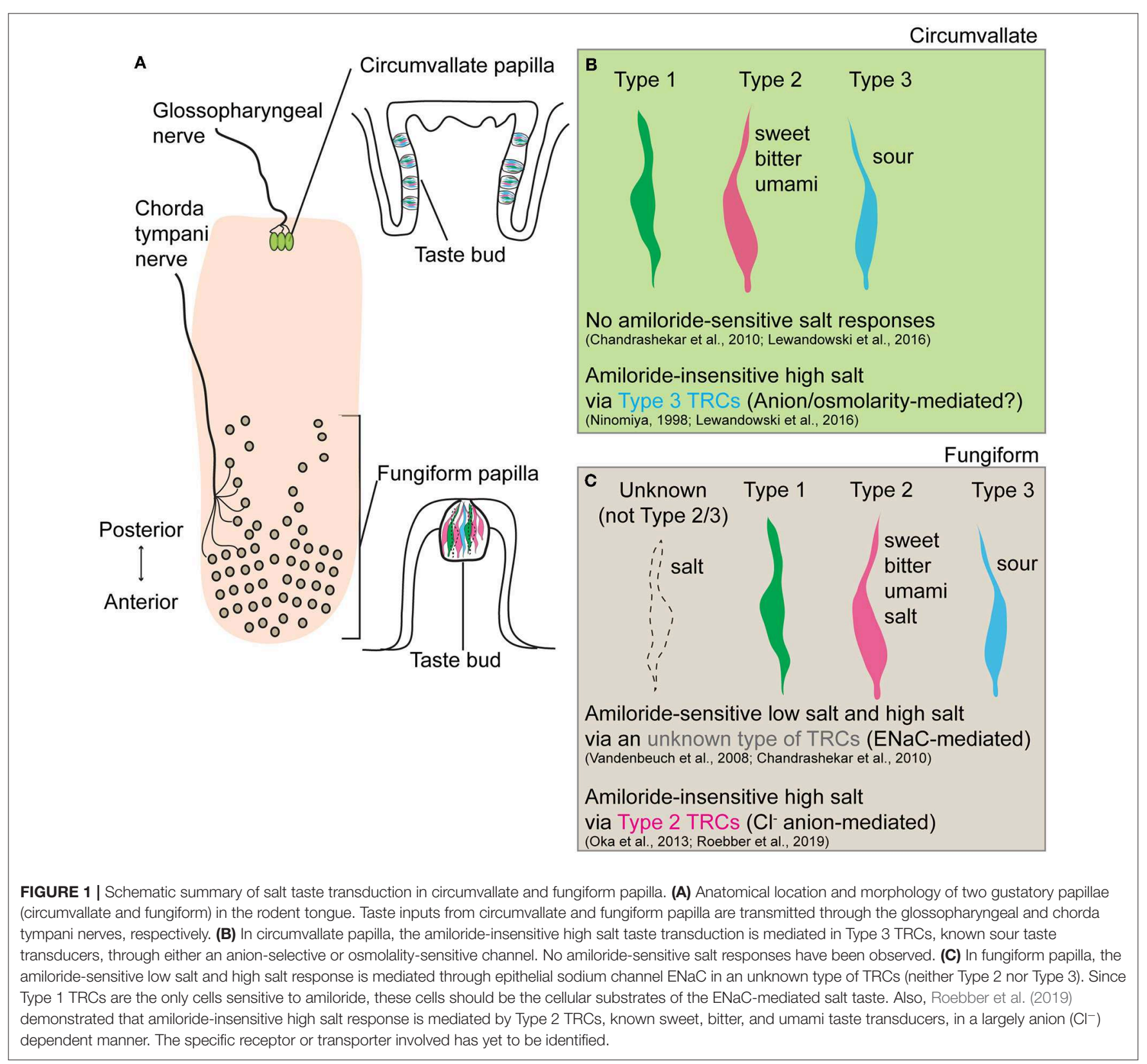


showing that bitter-sensing Type 2 TRCs also exhibit amilorideinsensitive high salt responses (Oka et al., 2013). Since saccharin activates both sweet and bitter taste receptors (Kuhn et al., 2004), it is unclear whether the Type 2 TRCs that respond to both $\mathrm{NaCl}$ and saccharin represent bitter TRCs or whether they comprise both sweet and bitter TRCs. It has been proposed that high salt co-opts the bitter transduction pathway to ensure robust behavioral aversion (Oka et al., 2013); however, a recent study in Drosophila reported that peripheral gustatory sweet-sensing neurons are also activated by high concentrations of $\mathrm{NaCl}$ (Jaeger et al., 2018). An intriguing parallel is that mammalian TRCs for appetitive tastes, such as sweet or umami, might also respond to high salt. Consistent with this possibility, Roebber et al. (2019) found that 9 out of 35 imaged TRCs responded only to high salt but not to saccharin or the bitter mixture, suggesting that they may be Type 2 TRCs for umami taste. Future experiments with imaging the same taste bud with sequential application of $\mathrm{NaCl}$ and either sweet or umami substances would clarify the involvement of each subset of Type 2 TRCs in high salt responses.

In contrast, the authors showed that citric acid, a tastant known to activate Type 3 TRCs, did not activate any cells that responded to $\mathrm{NaCl}$, consistent with previous $\mathrm{Ca}^{2+}$ imaging results that found distinct populations of TRCs responding to high salt and sour stimuli (Chandrashekar et al., 2010). Intriguingly, another study reported that blocking synaptic transmission of Type 3 sour cells (PKD2L1-expressing cells) by expression of the tetanus toxin light chain reduced amilorideinsensitive high salt responses in the chorda tympani nerve, indicating the role of Type 3 sour cells in high salt detection (Oka et al., 2013). Given the lack of functional imaging evidence for overlap of high salt and sour receptivity in the taste buds, one possibility is that rather than acting as direct high salt sensors, Type 3 sour cells modulate high salt responses through interaction with other types of TRCs via gap junctions or paracrine signaling (Roper and Chaudhari, 2017). Taken together, the results provided by Roebber et al. (2019) strengthen the idea that Type 2 TRCs are the cellular substrates for amiloride-insensitive high salt responses in fungiform papilla.

To explore the molecular mechanism underlying the amiloride-insensitive high salt responses in fungiform papilla, the authors substituted choline chloride for $\mathrm{NaCl}$ and found that choline chloride yielded $\mathrm{Ca}^{2+}$ responses comparable to those of $\mathrm{NaCl}$ in both the presence and absence of extracellular $\mathrm{Na}^{+}$. In addition, when Na-gluconate was substituted for $\mathrm{NaCl}, \mathrm{Ca}^{2+}$ responses were totally abolished, suggesting $\mathrm{Cl}^{-}$but not $\mathrm{Na}^{+}$plays a major role in amiloride-insensitive high salt responses (Roebber et al., 2019). Although $\mathrm{Cl}^{-}$is essential for high salt responses, a broader role of the anion

\section{REFERENCES}

Aaron, K. J., and Sanders, P. W. (2013). Role of dietary salt and potassium intake in cardiovascular health and disease: a review of the evidence. Mayo Clin. Proc. 88, 987-995. doi: 10.1016/j.mayocp.2013.06.005

Beidler, L. M. (1953). Properties of chemoreceptors of tongue of rat. J. Neurophysiol. 16, 595-607. doi: 10.1152/jn.1953.16.6.595 in high salt responses cannot be ruled out since $\mathrm{NaBr}$ elicited a partial response as compared to $\mathrm{NaCl}$, consistent with an ability of other anions to elicit high salt responses. This may explain why the authors could not identify the molecular machinery underlying high salt transduction using a candidate gene approach targeting $\mathrm{Cl}^{-}$channels or transporters with pharmacological inhibitors and ion substitution experiments (Roebber et al., 2019). In addition, the contribution of the cation remains unclear since substituting $\mathrm{KCl}$ for $\mathrm{NaCl}$ reduced high salt responses by $50 \%$ (Roebber et al., 2019). It is possible that $\mathrm{K}^{+}$, but not $\mathrm{Na}^{+}$, interferes with unidentified anion-mediated salt transduction machinery, conceivably anion-selective channels such as Pannexin 1 or Cystic fibrosis transmembrane conductance regulator (CFTR), which are known to be expressed in rodent taste buds (Huang et al., 2007; Merigo et al., 2008; Ma et al., 2012; Hwang and Kirk, 2013). Identifying the molecular underpinnings of anion-mediated salt transduction would provide further insight into how $\mathrm{K}^{+}$interacts with this pathway.

In conclusion, Roebber et al. (2019) demonstrated that Type 2 TRCs in fungiform papillae mediate amilorideinsensitive high salt responses that are predominantly driven by the $\mathrm{Cl}^{-}$anion. This work provides an important step toward the full picture of how different concentrations of salts are differentially encoded in the gustatory system. Together with prior findings that amiloride-insensitive high salt responses were observed in Type 3 TRCs of the circumvallate papillae (Ninomiya, 1998; Lewandowski et al., 2016), it is intriguing that salt taste coding varies across different types of TRCs in anatomically and functionally distinct gustatory papillae (Figure 1). Future studies to investigate molecular machinery underlying individual salt transduction pathways, and mechanisms by which animals integrate salt-sensing inputs to generate opposite behavioral responses to low salt and high salt would inform strategies to reduce overconsumption of dietary salt.

\section{AUTHOR CONTRIBUTIONS}

VM and Y-CC contributed ideas and wrote the final manuscript.

\section{ACKNOWLEDGMENTS}

We thank Drs. Anupama Dahanukar, David Hill, Robin Dando, Steven Munger as well as Mr. Jonathan Clark for their helpful comments and editorial assistance on the manuscript. Y-CC was a Howard Hughes Medical Institute International Student Research Fellow. 
Huang, Y. J., Maruyama, Y., Dvoryanchikov, G., Pereira, E., Chaudhari, N., and Roper, S. D. (2007). The role of pannexin 1 hemichannels in ATP release and cell-cell communication in mouse taste buds. Proc. Natl. Acad. Sci. U.S.A. 104, 6436-6441. doi: 10.1073/pnas.0611280104

Hwang, T. C., and Kirk, K. L. (2013). The CFTR ion channel: gating, regulation, and anion permeation. Cold Spring Harb. Perspect. Med. 3:a009498. doi: $10.1101 /$ cshperspect.a009498

Jaeger, A. H., Stanley, M., Weiss, Z. F., Musso, P. Y., Chan, R. C., Zhang, H., et al. (2018). A complex peripheral code for salt taste in Drosophila. Elife 7:e37167. doi: 10.7554/eLife.37167

Kuhn, C., Bufe, B., Winnig, M., Hofmann, T., Frank, O., Behrens, M., et al. (2004). Bitter taste receptors for saccharin and acesulfame K. J. Neurosci. 24, 10260-10265. doi: 10.1523/JNEUROSCI.1225-04.2004

Lewandowski, B. C., Sukumaran, S. K., Margolskee, R. F., and Bachmanov, A. A. (2016). Amiloride-insensitive salt taste is mediated by two populations of type III taste cells with distinct transduction mechanisms. J. Neurosci. 36, 1942-1953. doi: 10.1523/JNEUROSCI.2947-15.2016

Liman, E. R., Zhang, Y. V., and Montell, C. (2014). Peripheral coding of taste. Neuron 81, 984-1000. doi: 10.1016/j.neuron.2014.02.022

Lu, B., Breza, J. M., and Contreras, R. J. (2016). Temperature influences chorda tympani nerve responses to sweet, salty, sour, umami, and bitter stimuli in mice. Chem. Senses 41, 727-736. doi: 10.1093/chemse/bjw082

Ma, W., Compan, V., Zheng, W., Martin, E., North, R. A., Verkhratsky, A., et al. (2012). Pannexin 1 forms an anion-selective channel. Pflugers Arch. 463, 585-592. doi: 10.1007/s00424-012-1077-z

Merigo, F., Benati, D., Galie, M., Crescimanno, C., Osculati, F., and Sbarbati, A. (2008). Immunohistochemical localization of cystic fibrosis transmembrane regulator and clara cell secretory protein in taste receptor cells of rat circumvallate papillae. Chem. Senses 33, 231-241. doi: 10.1093/chemse/bjm082

Ninomiya, Y. (1998). Reinnervation of cross-regenerated gustatory nerve fibers into amiloride-sensitive and amiloride-insensitive taste receptor cells. Proc. Natl. Acad. Sci. U.S.A. 95, 5347-5350. doi: 10.1073/pnas.95.9.5347
Oka, Y., Butnaru, M., von Buchholtz, L., Ryba, N. J., and Zuker, C. S. (2013). High salt recruits aversive taste pathways. Nature 494, 472-475. doi: 10.1038/nature11905

Roebber, J. K., Roper, S. D., and Chaudhari, N. (2019). The role of the anion in salt $(\mathrm{NaCl})$ detection by mouse taste buds. J. Neurosci. 39, 6224-6232. doi: 10.1523/JNEUROSCI.2367-18.2019

Roper, S. D., and Chaudhari, N. (2017). Taste buds: cells, signals and synapses. Nat. Rev. Neurosci. 18, 485-497. doi: 10.1038/nrn.2017.68

Schulkin, J. (1991). Sodium Hunger : The Search for a Salty Taste. Cambridge, NY: Cambridge University Press.

Tu, Y. H., Cooper, A. J., Teng, B., Chang, R. B., Artiga, D. J., Turner, H. N., et al. (2018). An evolutionarily conserved gene family encodes proton-selective ion channels. Science 359, 1047-1050. doi: 10.1126/science. aao3264

Vandenbeuch, A., Clapp, T. R., and Kinnamon, S. C. (2008). Amiloride-sensitive channels in type I fungiform taste cells in mouse. BMC Neurosci. 9:1. doi: 10.1186/1471-2202-9-1

Yoshida, R., Horio, N., Murata, Y., Yasumatsu, K., Shigemura, N., and Ninomiya, Y. (2009). NaCl responsive taste cells in the mouse fungiform taste buds. Neuroscience 159, 795-803. doi: 10.1016/j.neuroscience.2008. 12.052

Conflict of Interest: The authors declare that the research was conducted in the absence of any commercial or financial relationships that could be construed as a potential conflict of interest.

Copyright (c) 2019 Menon and Chen. This is an open-access article distributed under the terms of the Creative Commons Attribution License (CC BY). The use, distribution or reproduction in other forums is permitted, provided the original author(s) and the copyright owner(s) are credited and that the original publication in this journal is cited, in accordance with accepted academic practice. No use, distribution or reproduction is permitted which does not comply with these terms. 